\title{
Design and characterization of a portable heat storage facility
}

\author{
Nadjiba Mahfoudi ${ }^{1, a}$, Abderahman Khachkouch ${ }^{2}$, Abdelhafid Moummi ${ }^{1}$, \\ Boubaker Benhaoua ${ }^{3}$ And Mohamed El Ganaoui ${ }^{4}$ \\ 1 Laboratoire de Génie Civil, Hydraulique, Développement Durable et Environnement, (LAR-GHYDE), Université Mohamed \\ Khider, BP 145, 07000 Biskra, Algérie \\ 2 Université d'El Oued, PO Box 789, 39000 El Oued, Algérie \\ 3 Laboratoire de valorisation des technologies des ressources sahariennes (VTRS), Université d'El Oued, PO Box 789, \\ 39000 El Oued, Algérie \\ 4 Université de Lorraine, Laboratoire d'Energétique de Longwy/LERMAB, IUT Henri Poincaré de Longwy, 186 rue de Lorraine, \\ 54400 Cosnes Et Romain, France
}

Received 19 July 2014, Accepted 6 February 2015

\begin{abstract}
This paper deals with the experimental investigation of transient behavior and thermal storage capability of a sensible heat storage unit. The former is designed to store solar energy by using sand as a storage medium. A cubic unit has been designed employing three configurations of embedded charging tubes to study the performances of the system. The storage material used in this experimentation (sand) has been characterized by its, grain size, density, and heat capacity. Performances of the thermal storage bed (including charging time, energy stored rate, charging energy efficiency) have been evaluated for selecting the storage material. From our experiments, we found that the number of charging tubes affects significantly the storage performances.
\end{abstract}

Key words: Heat storage / characterization / design / sand / thermal behavior

\section{Nomenclature}

\begin{tabular}{|ll|}
\hline$C_{p}$ & Specific heat of the storage medium $\left(\mathrm{J}_{\mathrm{kg}}{ }^{-1} \cdot \mathrm{K}^{-1}\right)$ \\
$m$ & Mass of the storage medium $(\mathrm{kg})$ \\
$Q$ & Heat storage capacity $(\mathrm{J})$ \\
$t$ & Time (hour) \\
$T$ & Temperature $\left({ }^{\circ} \mathrm{C}\right)$ \\
$T_{\mathrm{f}}$ & Final temperature $\left({ }^{\circ} \mathrm{C}\right)$ \\
$T_{\mathrm{i}}$ & Initial temperature $\left({ }^{\circ} \mathrm{C}\right)$ \\
$T_{\text {ini }}$ & Initial temperature of storage bed $\left({ }^{\circ} \mathrm{C}\right)$ \\
$T_{\text {inlet }}$ & HTF inlet temperature $\left({ }^{\circ} \mathrm{C}\right)$ \\
\hline
\end{tabular}

\section{Introduction}

The world is turning to renewable energy due to the increasing importance for environmental protection and rising energy costs. In particular, solar energy being inexhaustible and available for free, has received a wide spread of attention recently. But its intermittent feature induces

\footnotetext{
${ }^{a}$ Corresponding author: Nadjiba213@Yahoo.fr
}

serious limitations in any potential applications. This involves the development of systems that ensure the storage of excess heat collected during periods of bright sunshine, to be later released for use during night or other, as well as Thermal Energy Storage system (TES).

The main factors that hamper the development of TES are their less efficiency and high cost [1]. The good choice of the storage medium is a one of the efficient ways that reduce significantly the cost of TES devices [2].

In general, there are three concepts of thermal storage systems: sensible heat storage, latent heat storage, and thermo- chemical energy storage [1].

In Figure 1 [3], we present an overview of the major technique used in the storage of the thermal-based solar energy. In sensible heat storage (SHS) systems, thermal energy is stored by rising the temperature of the solid or liquid, using the heat capacity and change in temperature of the material during the process of charging and discharging. Latent heat storage (LHS) is the heat absorption or release when a storage material undergoes a change of phase from solid to liquid or liquid to gas or vice versa at more or less constant temperature. In the case of the thermo-chemical systems (TCES), the heat is 


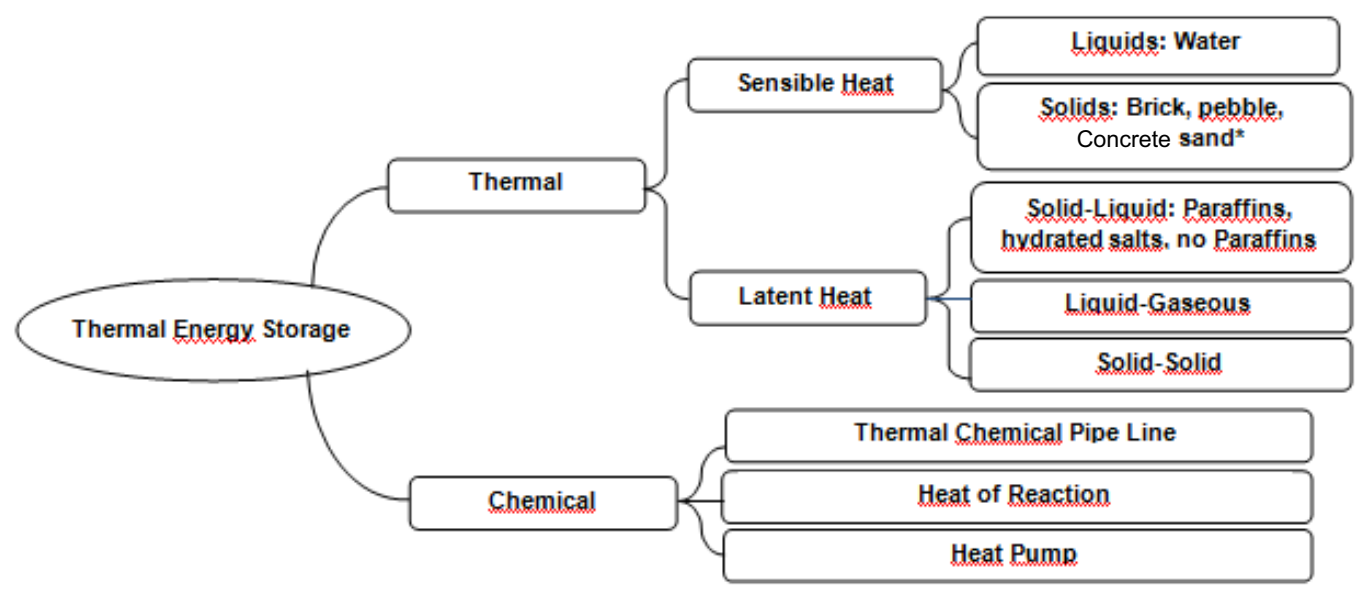

Fig. 1. Overview of thermal energy storage technique in the solar systems.

when the molecular bonds are breaking and reforming in a reversible chemical reaction.

As the most simple and cheap way to store energy, sensible heat storage has been used for a long time in worldwide. Considering the technological maturity and economical aspect, SHS is superior compared with latent and chemical heat storage.

A promising sensible heat storage medium must also be inexpensive and have a good energy density, which is the heat capacity per unit volume. Until now water, molten salt, synthetic oil, cast steel, stone, rock, sand, concrete and ceramic have been selected as sensible heat storage medium depending on the temperature range and application [4].

In the applications with low temperature such as space heating, water heating, solar desalination etc. the solid materials (rock, sand, gravel, concrete) are widely used as medium for thermal storage [5]. Due to its good thermal inertia [6], sand, is one of the materials that's used as a storage medium in low and high temperature applications [7-10].

The TES systems using solid materials as a sensible heat storage medium, is usually implemented by embedding heat exchanger tubes in the medium to transfer thermal energy to/from heat transfer fluid [3]. In this work sand has been used as a storage medium for a solar application designed to acontinuous drying of agricultural food products at steady state and moderate temperature $\left(40-75^{\circ} \mathrm{C}\right)$. A thermal analysis is presented.

\section{Basic consideration on the sensible heat storage systems}

Though the sensible thermal storage has the advantages of high reliability, simpler structure and operation compared with the latent storage, the amount of heat stored depends on the specific heat of the medium, the temperature change and the amount of storage material [11].
Thus it is desirable for the storage medium to have high specific heat capacity, long term stability under thermal cycling, compatibility with its containment and, most important low cost [12].

Sensible heat storage may be classified as the basis of heat storage medium as liquid and solid medium storage.

As a definition of the sensible heat storage materials is a group of materials that undergo no phase change within the temperature range required for the storage process [13]. The number of available materials is more than 150000 , with new ones appearing every year [14].

Heat storage liquids are plentiful and economically competitive. At low temperature, the water is one of the best storage medium. Because of its high capacity to store

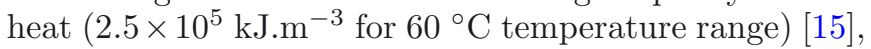
water is the most widely used storage medium today for solar based warm water and space heating application.

Petroleum based oils and molten salts are the most commonly proposed substitutes for water. There heat capacities are $25-40 \%$ of that of water on weight basis. However, these substitutes have lower pressure vapor than water and they are capable of operating at high temperature exceeding $300{ }^{\circ} \mathrm{C}[16]$.

Storing thermal energy as sensible heat in solids can remedy to the difficulties of the high pressure vapor of water and the limitations of other liquids. However, for a low as well as high temperature thermal energy storage, solid materials such as rocks, metal, concrete, sand, brick etc., can be used.

Solar energy can also be stored in rock or pebbles (packed in insulated vessels), and it is convenient for use in buildings. This kind of storage is operated very often for temperature up to $100{ }^{\circ} \mathrm{C}$ in conjugate with solar air heater [17]. For a temperature change of $50^{\circ} \mathrm{C}$, rocks and

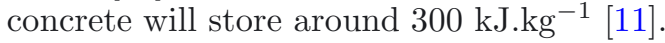

Like fixed beds (rocks, pebbles, sand...), fluidized beds can be utilized for low, intermediumte and high temperature solar applications. In addition, the rate of heating exchanges between the storage medium and the heat carrying fluid is much faster in fluidized beds than in fixed ones, which can be an advantage in several applications 

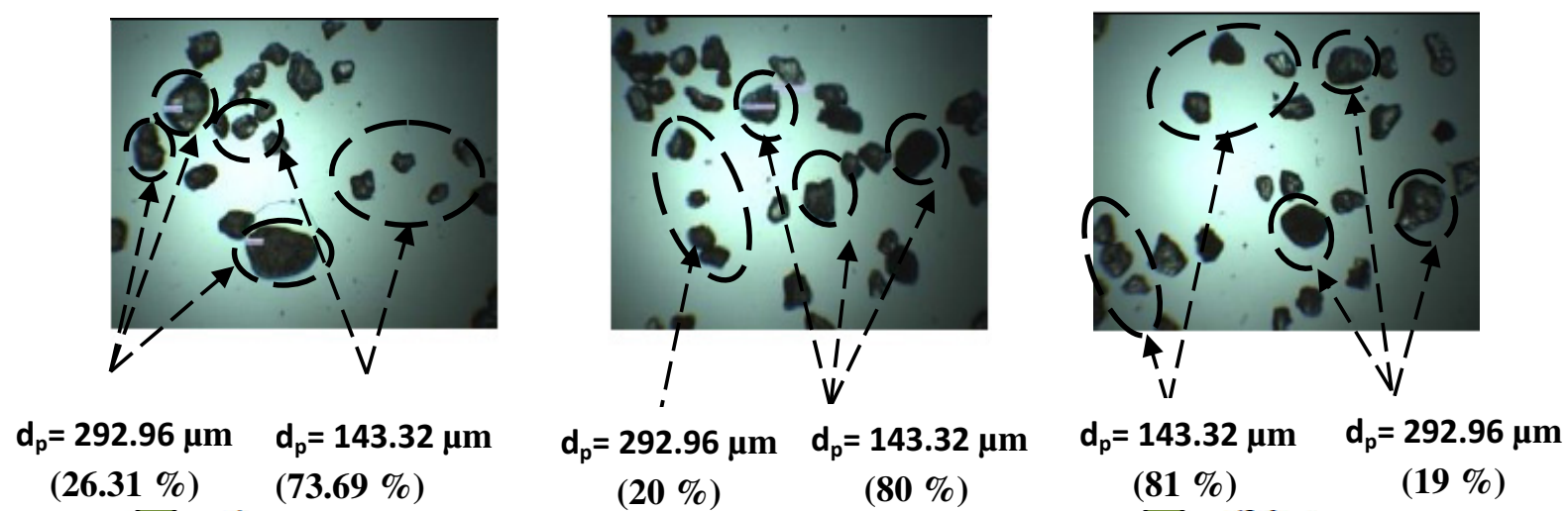

Fig. 2. Photographic view of grains size distribution in sand's samples.

as drying foods or wood [18-20]. In fluidized beds thermal storage can also be used for waste heat recovery purposes [13].

Metal storage medium proposed for high temperature $\left(120-1400^{\circ} \mathrm{C}\right)$ are either inorganic salts or metals.

Thus, the attractive characteristics of the sensible storage material include, high thermal heat capacity, high density, high thermal diffusivity, chemical and geometrical stability, reversible heating and cooling, non corrosive and no toxic, low vapor pressure and low cost of material and storage fabrication [21].

In this paper, sand has been used as a storage medium, which largely satisfies the above criteria.

\section{An example of designing a storage facility}

In the design of the solar thermal energy storage systems, there are three aspects that need to be considered: technical properties, cost effectiveness and environmental impact $[16,22]$.

From the technical point of view: a high thermal storage capacity is essential to reduce the system volume and increase the system efficiency. A good heat transfer rate must be maintained between the heat storage material and the heat carried fluid in order to ensure the required speed such that thermal energy can be released/absorbed.

On the other hand, the cost of solar thermal storage system mainly consists of three points: storage material, heat exchanger and land cost.

To design a heat storage system, it is necessary to have an optimum of all the above listed criteria.

In the case of liquid storage system, for example, water tanks are made from a wide variety of materials, like reinforced concrete, Aluminium, Steel, and fiber glass. There insulation is assured by mineral wool, glass wool or Polyurethan. The size of the tanks used varies from a few of hundred litres to a few thousand cubic meters.

Peiwen Li et al. [23] have given the charts that will serve as standard tool to design and calibrate the size of the heat storage tanks and operational conditions for thermal storage system.
To show the interest to develop the solar heat storage system in the region where both sand and sun were plentiful, a CFD simulation is carried out to understand the thermal behavior and to underline the storage capability of a sensible storage unit using sand for solar applications $[24,25]$. As a result, the bed temperature leads to higher energy efficiency and the thermal inertia of the system remains important after various charge/discharge cycles.

\section{Experimentation}

\subsection{Sand characterization}

In the present work, the storage medium used is dune sand of south of Algeria (El-Oued region). For this reason a characterization study has been indispensable to determine the sand's properties (grain size, density, heat capacity).

Dune sand is mainly composed of quartz grain, $\mathrm{Fe}_{2} \mathrm{O}_{3}$, $\mathrm{CaCO}_{3}, \mathrm{Al}_{2} \mathrm{O}_{3}$, some impurities and heavy materials [26]. One of the properties that characterize the dune sand is its fine grain size [27].

To determine the sand grain size, an optic microscope has been used to visualize the different grains size in the sample of sand (Fig. 2).

The grain size analysis shows that the sand of El-Oued region is composed of $22 \%$ of grain with particle diameter of $292.96 \mu \mathrm{m}$, and $78 \%$ with particle diameter of $143.32 \mu \mathrm{m}$.

To find the density of the sand, a different mass was taken; there volume was measured by using gradual tube. As the result, the density of El-Oued sand is $2700 \mathrm{~kg} . \mathrm{m}^{-3}$.

The thermal capacity of sand is obtained by, firstly weighing measuring different masses of sand and measuring their initial temperatures, then adding the hot distilled water (heated until boiling temperature) to the sand, and wetting equilibrium state. By using Equation (1), we found that the heat capacity of the sand is $920 \mathrm{~J} . \mathrm{kg}^{-1}$.

$$
Q=m c_{p}\left(T_{\mathrm{f}}-T_{\mathrm{i}}\right)
$$




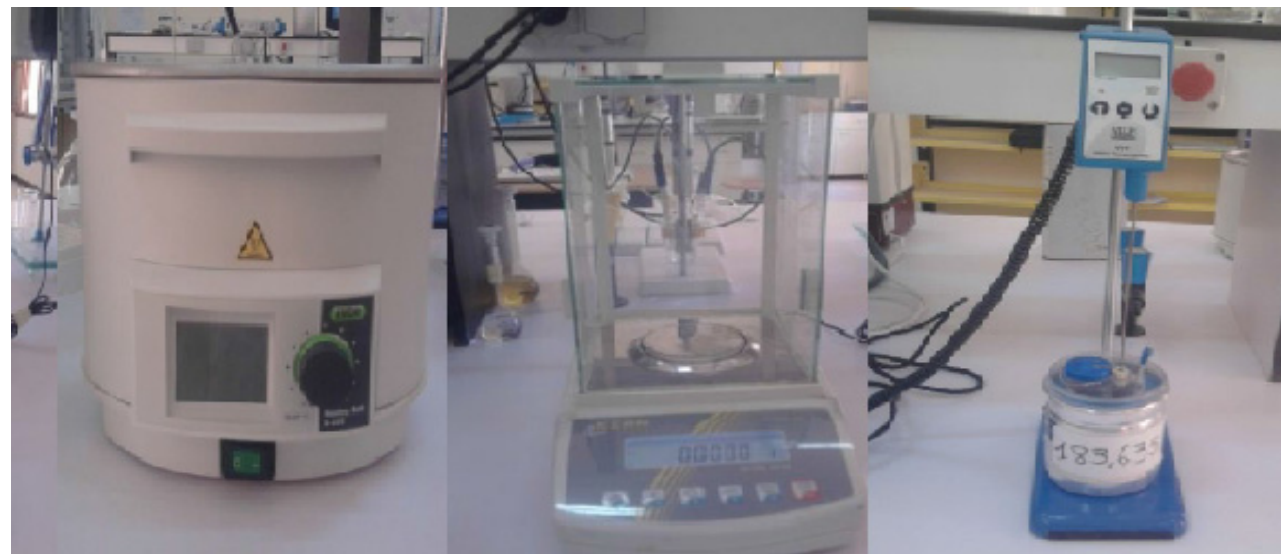

(1)

Electrical heater
(2)

Electronical balance
(3)

Fig. 3. Materials used for heat capacity measurement.

The different devices used for this experiment are shown in Figure 3.

In conclusion, such as, the sand of El-Oued region has a density of $2700 \mathrm{~kg} \cdot \mathrm{m}^{-3}$, a specific heat of $920 \mathrm{~J} . \mathrm{kg}^{-1} \cdot \mathrm{K}^{-1}$ and a grain diameter between 143.32 and $292.96 \mu \mathrm{m}$.

\subsection{Thermal storage system}

The storage system consists of an air plate collector, thermal storage unit with heat exchange, thermocouples and temperature indicator. The schematic overview of the experimental device is shown in Figure 4.

The storage device has a cubic shape with $60 \mathrm{~cm}$ of dimension where the cooper tubes with $2.2 \mathrm{~cm}$ of diameter and $40 \mathrm{~cm}$ of length are embedded. The unit is well insulated. The storage unit filled with $120 \mathrm{~kg}$ of sand is connected to the solar collector. The solar thermal system was experimented with three different configurations of the heat exchanger (4, 9, 12 tubes) and the temperature variations are taken during charging time.

To determine the performance of the storage system, it is necessary to calculate the charging energy efficiency. It is based on the first law of thermodynamics which accounts for the storage material's capability to gain the thermal energy from HTF (Heat Transfer Fluid). The charging energy efficiency is the ratio of the actual energy stored by the storage material to the maximum energy available as input to storage material (Eq. (2)) [28].

$$
\eta=\frac{T(t)-T_{\mathrm{ini}}}{T_{\mathrm{inlet}}-T_{\mathrm{ini}}}
$$

where $T(t)$ is the volume average temperature of storage bed and is a function of time, $T_{\text {ini }}$ and $T_{\text {inlet }}$ are the initial temperature of the bed and the HTF inlet temperature, respectively.

\section{Results and discussions}

The experimental results are enumerated in the form of various graphs of temperature variations where the effect of the number of charging tubes is studied.

Figure 5 presents the sand temperature measured during the charging process for HTF inlet temperature of $70{ }^{\circ} \mathrm{C}$, and four charging tubes. The sand temperature has been noted for every hour. The storage bed is said to be charged when its temperature became constant. It is seen from the figure that the sand temperature increases gradually to reach the maximum value where it stabilizes (up to $36^{\circ} \mathrm{C}$ ). The sand bed takes about $5 \mathrm{~h} \mathrm{~s}$ for a complete charging in these operating conditions. It is observed that rise of the sand temperature is slow in the time interval from $9 \mathrm{~h}$ to $10 \mathrm{~h}$ and from $13 \mathrm{~h}$ to $14 \mathrm{~h}$; on the other hand, it is rapid from $10 \mathrm{~h}$ to $13 \mathrm{~h}$. The slow behavior of the temperature variation is due to a slow variation in solar intensity during these time intervals, in contrast, the rapid one is due to the rapid variation in the solar intensity in the last interval. From $14 \mathrm{~h}$ to $17 \mathrm{~h}$ the sand bed has an isothermal behavior because it is fully charged.

The bed temperature variation during two consecutive days is presented in Figure 6. It is noticed that the sand temperature decreases slowly during no charging period (no sun period) to reach $\sim 34{ }^{\circ} \mathrm{C}$. It is also noticed that the sand temperature decreases $2{ }^{\circ} \mathrm{C}$ during interval time of $17 \mathrm{~h}$.

Since the CEE is in function of the temperature storage bed, it varies in the same fashion as the rate of charging the storage bed.

In order to study the effect of the number of charging tubes, the bed temperature for three configurations of charging tubes is presented in Figure 7. It is seen from Figure 7 that increasing the number of charging tubes accelerates the heat transfer rate into storage bed resulting into faster temperature rise of storage bed. Between both 
N. Mahfoudi et al.: Mechanics \& Industry 16, 411 (2015)

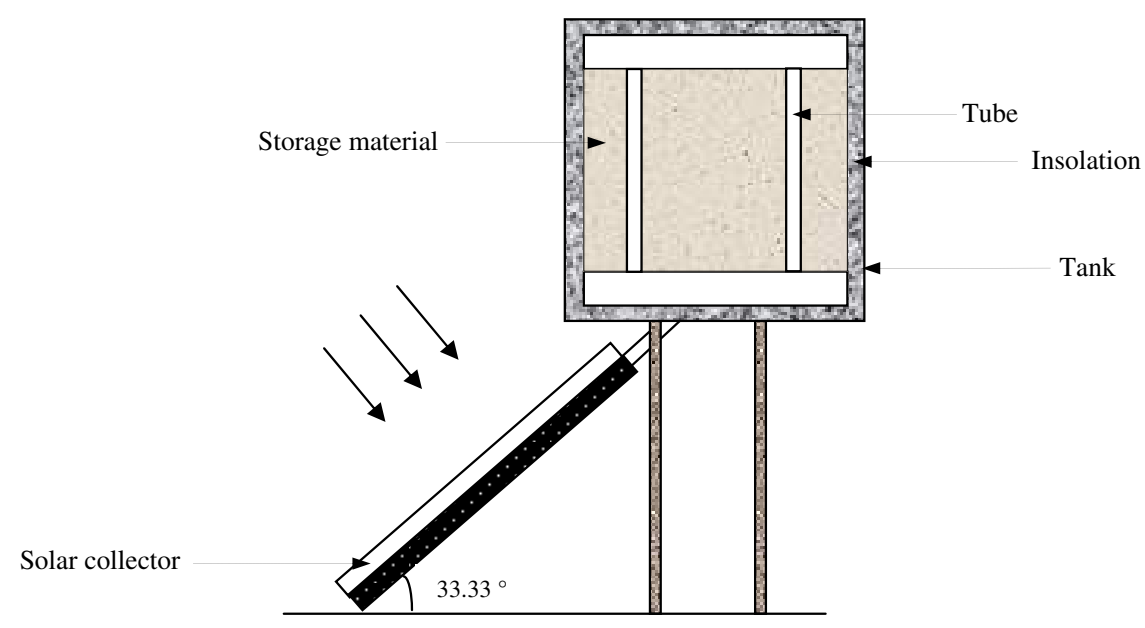

Fig. 4. Schematic diagram of the experimental device.

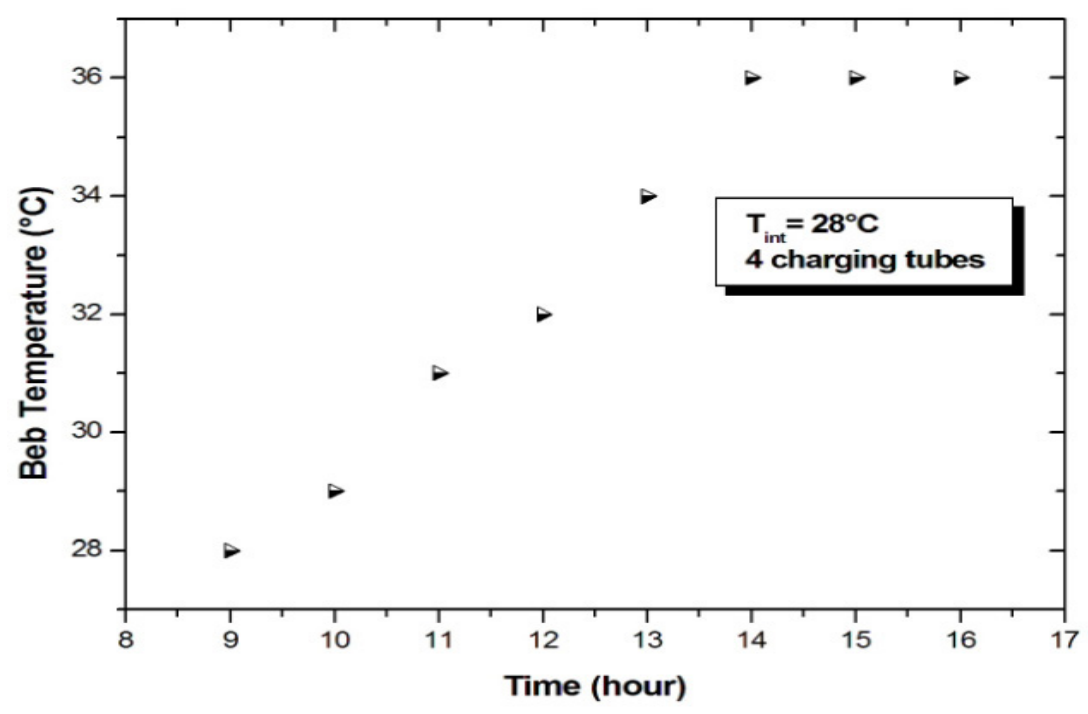

Fig. 5. Experimental sand temperature during charging.

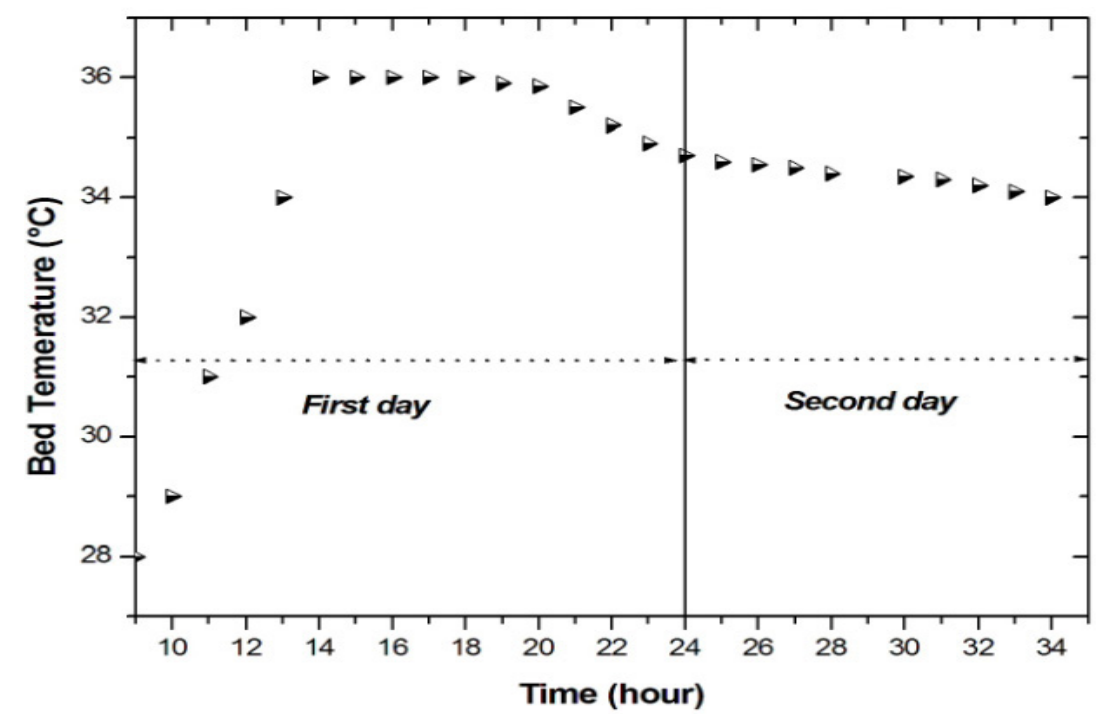

Fig. 6. Variation of the bed temperature during two consecutive days. 


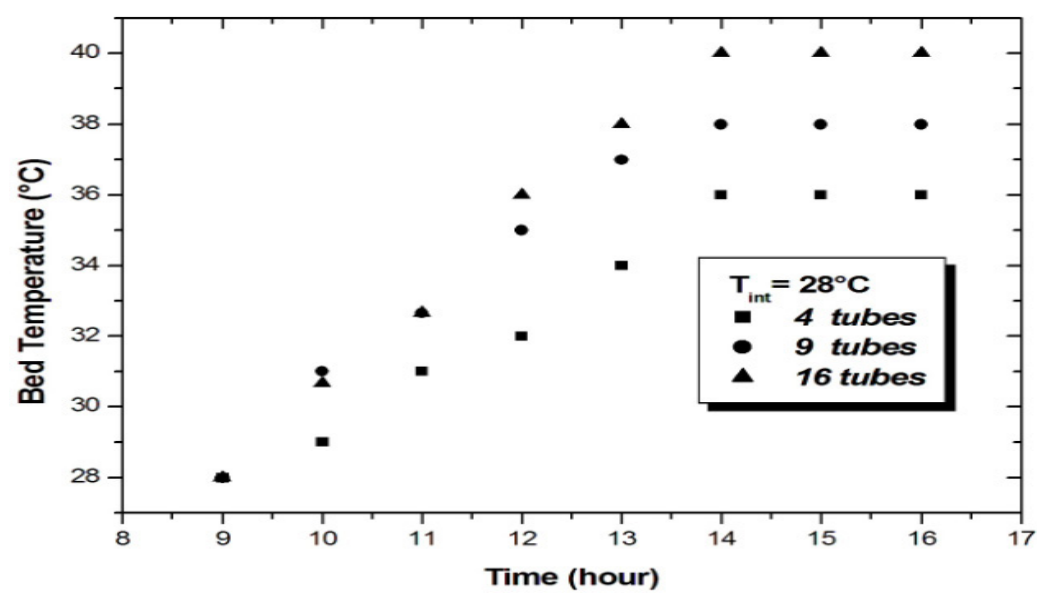

Fig. 7. Effect of number of charging tubes on bed temperature.

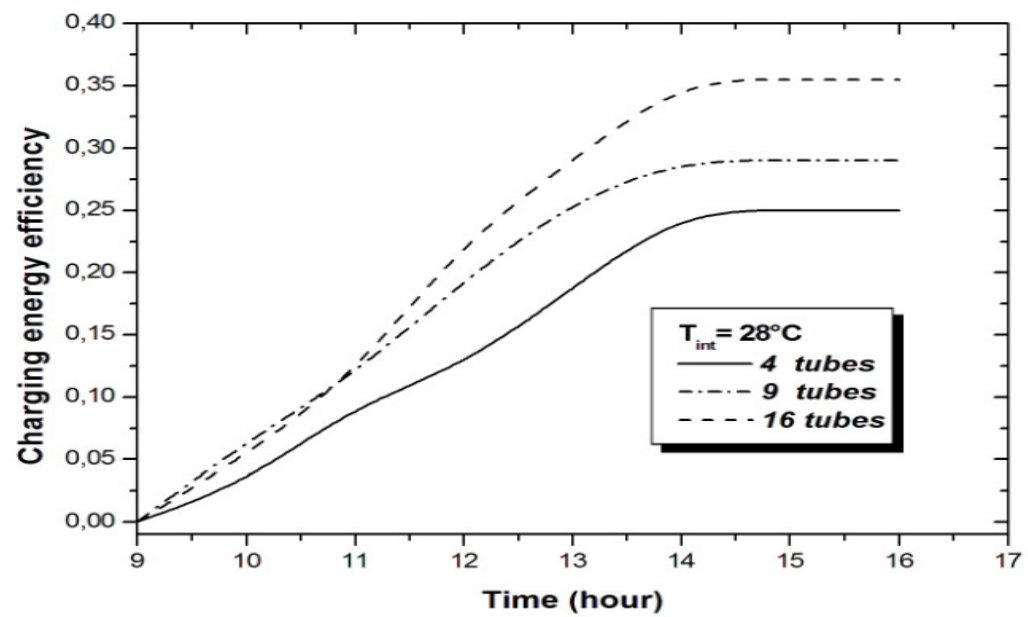

Fig. 8. Charging energy efficiency of sand bed depending on number of charging tubes.

configurations, 9 and 16 tubes, bed temperature does not vary significantly.

Figure 8 illustrates the variation of the bed efficiency as function of the number of charging tubes. In the case with four charging tubes, sand bed is able to store $20 \%$ of the heat carried by the HTF. In contrast, CEE increases up to $\sim 40 \%$ with 16 charging tubes.

\section{Conclusion}

In this paper, a design and a characterization of sensible portable heat storage unit of cubical configuration employing sand as storage medium have been presented. First experiments are conducted on the TES unit to study its performance by integrating with the solar flat plate collector. Before that the material used as a storage medium (sand of El-Oued region, south of Algeria) has been characterized. A large thermal inertia of the system corresponding to the duration of its discharging is shown. The energy stored and the charging efficiency can be increased by rising the number of charging tubes. The configuration with 9 tubes can be a good choice to optimize cost of heat exchanger. It is concluded that is appreciable to use sand as a storage medium for application where the requirement is intermittent. However a numerical modeling will allow to optimize the system and to determine the operating conditions for optimal performances.

Acknowledgements. The authors are grateful to the partners who contributed to this study, the PNR AlgéroFrançais program as well as the IUT of Longwy (Laboratoire d'Energétique/LERMAB) and PHC Hubert Curien Project.

\section{References}

[1] D. Ibrahim, A.R. Marc, Thermal energy storage system and application, Wiley, 2011, pp. 90-99

[2] S. Khare, M. Dell Amico, C. Knight, S. McGarry, Selection of materials for high temperature sensible energy storage, Sol. Energy Mater. Solar Cells 115 (2013) $114-122$

[3] S. Harmeet, R.P. Saini, J.S. Saini, A review on packed bed solar energy storage systems, Renew. Sust. Energ. Rev. 14 (2010) 1059-1069 
[4] B. Fengwu, X. Chao, Performance analysis of a two-stage thermal energy storage system using concrete and steam accumulator, Appl. Thermal Eng. 31 (2011) 2764-2771

[5] M.M. Elsayed, I.E. Megahed, M.M. El-Refaee, Experimental testing of fluidized bed thermal storage, Solar and Wind Technology 5 (1988) 15-25

[6] S. Hassan, R.S. Hernandez, K. Vonzabern, J. Pierce, K. Kantesaria, M. Rubin, Thermal Inertia of sand at different Levels of Water Saturation, 44th Lunar and Planetary science Conference, 2013

[7] M. Haider, K. Schwaiger, F. Holzlethner, R. Eisl, A comparaison between passive regenerative and active fluidized bed thermal energy storage systems, J. Phys.: Conf. Ser. 395 (2012) 8

[8] S. Warerkar, S. Schmitz, J. Goettsche, B. Hoffschmidt, M. Rei $\beta$ el, Air-Sand Heat Exchanger for High-Temperature Storage, J. Solar Energy Eng. 133 (2011) 021010-1021010-7

[9] J. Sheldon, D. Sadowski, M. Golob, J. McKoy, J. Stephens, B. Lines, Development of a novel thermal energy storage system using sand as the medium, The Solar Conference Proceedings, 2010

[10] B. Nordell, G. Hellstrom, High temperature solar heated seasonal storage system for low temperature heating of buildings, Solar Energy 69 (2000) 511-523

[11] M.B. Lalit, S. Santosh, S.N. Naik, Solar dryer with thermal energy storage systems for drying agricultural food products: A review, Renew. Sust. Energ. Rev. 14 (2010) 2298-2314

[12] S.H. Hasnain, Review on sustainable thermal energy storage technologies, part i: heat storage materials and techniques, Energy Convers. Mgmt 39 (1998) 1127-1138

[13] D. Fernandes, F. Pitié, G. Cáceres, J. Baeyens, Thermal energy storage: How previous findings determine current research priorities, Energy 39 (2012) 246-257

[14] A.I. Fernandez, M. Martinez, M. Segarra, I. Martorell, L.F. Cabeza, Selection of materials with potential in sensible thermal energy storage, Solar Energy Mater. Solar Cells 94 (2010) 1723-1729

[15] M.E. Navarro, M. Martinez, A. Gil, A.I. Fernandez, L.F. Cabeza, R. Olives, X. Py, Selection and characterization of recycled materials for sensible thermal energy storage, Sol. Energy Mater. Sol Cells 107 (2012) 131-135

[16] A. Gil, M. Medrano, I. Martorell, A. Lazaro, P. Dolado, B. Zalba, L.F. Cabeza, State of the art on high temperature thermal energy storage for power generation, Part 1: Concepts, materials and modellization, Renew. Sust. Energ. Rev. 14 (2010) 31-55
[17] M.M. Alkilani, K. Sopian, M.A. Alghoul, M. Sohif, M.H. Ruslan, Review of solar air collectors with thermal storage units, Renew. Sust. Energ. Rev. 15 (2011) 1476-1490

[18] J.L. Tanguier, R. Benelmir, M. El Ganaoui, Fluidization of wood particles in a mixed bed: faisability and process control, Mechanics \& Industry 13 (2012) 69-76

[19] S. Messai, M. El Ganaoui, J. Sghaier, L. Chrusciel, S. Gabsi, Comparison of $1 \mathrm{D}$ and 2D models predicting a packed bed drying, Int. J. Simul. Multidiscipl. Design Optim. 14 (2014)

[20] S. Messai, J. Sghaier, L. Chrusciel, M. El Ganaoui, S. Gabsi, Low-Pressure Superheated Steam DryingVacuum Drying of a Porous medium and the Inversion Temperature, Drying echnology 33 (2015) 103-110 and $111-119$

[21] A.A. Arjun, R.W. Kishor, O.R. Rameshwar, Solar Thermal Storage System, Int. J. Theoret. Appl. Res. Mech. Eng. 1 (2012) 2319-3182

[22] Y. Tian, C.Y. Zhao, A review of solar collectors and thermal energy storage in solar thermal applications, Appl. Energy 104 (2013) 538-553

[23] P. Lia, J.V. Lewa, C. Chana, W. Karakia, J. Stephens, J.E. O'Brien, Similarity and generalized analysis of efficiencies of thermal energy storage systems, Renew. Energ. 39 (2012) 388-402

[24] N. Mahfoudi, A. Moummi, M. El. Ganaoui, Sand as a Heat Storage medium for a Solar Application: Simulation Results, Appl. Mech. Mater. 621 (2014) 214-220

[25] N. Mahfoudi, A. Moummi, M. El. Ganaoui, F. Mnasri, K.M. Aboudou, Simulation du comportement thermique d'un milieu poreux destiné au stockage sensible : Application à l'énergie solaire, CIFEM, 5-7 Mai 2014, Comores

[26] M. Fashby, D. Jones, Matériaux, Dunod, 1991, pp. 143157

[27] A. Bouaziz, R. Hamzaoui, S. Rezigue, A. Bennabi, Valorisation du sable de dune dans les formulations des mortiers et des bétons, 31èmes Rencontres de l'AUGC, E.N.S. Cachan, 29 au 31 mai, 2013

[28] M. Ashmore, H.T. Siemon, A comparison of experimental thermal stratification parameters for an oil/pebble-bed thermal energy storage (TES) system during charging, Appl. Energy 88 (2011) 4766-4778 